\title{
AITE Celebrates Its 70th Year of Publication (1953-2022)
}

\author{
Hubert Krotkiewski ${ }^{1} \cdot$ Michał Zimecki $^{1} \cdot$ Andrzej Górski $^{1}$
}

Published online: 9 December 2021

(c) L. Hirszfeld Institute of Immunology and Experimental Therapy, Wroclaw, Poland 2021

Dear Readers,

Archivum Immunologiae et Therapiae Experimentalis (AITE), founded in 1953 by professor Ludwik Hirszfeld, in the year 2022 publishes its 70th volume. Initially, the journal was published in Polish and was meant entirely as a local scientific journal with a limited expert audience. Since 1961, the AITE articles are in English. We recently published a brief history of the journal (Krotkiewski et al. 2018) which shows that AITE became an international journal, recognized among immunologists all over the world. The long, difficult, but successful route which the journal has taken is best reflected by the increase in its impact factor (IF) from the value of $\mathbf{0 . 1 0 4}$ in 1988 to $\mathbf{4 . 2 9 1}$ in 2020.

At present, AITE meets all the basic conditions of a modern and high-standard scientific journal with an international Advisory Board, recruitment of foreign reviewers, with the most advanced electronic tools used in the publication process, with the well-known Springer Nature Switzerland AG Publishing House. The journal publishes review and original articles in the field of clinical and experimental immunology, experimental therapy and related medical sciences. AITE should also be valued by exceptionally low auto-citation index (Górski et al. 2021). Taking the opportunity of the upcoming 70th anniversary, we wish to thank all our former Editors-in-Chief, the members of Advisory Board, our Authors and our Reviewers-all the people, who helped us to maintain a high scientific level of our articles. We do believe that the publishing future of AITE is optimistic.

\section{References}

Górski A, Zimecki M, Krotkiewski H (2021) Journal impact factor and self-citations. Arch Immunol Ther Exp 69:21

Krotkiewski H, Górski A, Zimecki M (2018) Building the prestige of Archivum Immunologiae et Therapiae Experimentalis: from a little known to an internationally recognized journal. Arch Immunol Ther Exp 66:407-413

Publisher's Note Springer Nature remains neutral with regard to jurisdictional claims in published maps and institutional affiliations.

Hubert Krotkiewski

hubert.krotkiewski@hirszfeld.pl

$1 \quad$ Hirszfeld Institute of Immunology and Experimental Therapy, Polish Academy of Sciences, Rudolfa Weigla 12, 53-114 Wrocław, Poland 